\title{
Blood glucose lowering activity of aloe based composition, UP780, in alloxan induced insulin dependent mouse diabetes model
}

\author{
Mesfin Yimam*, Jifu Zhao, Brandon Corneliusen, Mandee Pantier, Lidia Brownell and Qi Jia
}

\begin{abstract}
Background: There are a few nutritional approaches to address the increased needs of managing diabetic conditions. Previously it has been reported that UP780, a standardized composition of aloe chromone formulated with an aloe polysaccharide, has a significant impact in reducing $\mathrm{HbA1C}$, fasting blood glucose, fructosamine and plasma insulin level in humans and improved impaired glucose and insulin resistance in high-fat diet-induced and $\mathrm{db} / \mathrm{db}$ non-insulin dependent diabetic mouse models. Here we describe activity of UP780 and its constituents to improve insulin sensitivity in alloxan induced insulin dependent diabetic mouse model.
\end{abstract}

Materials and method: Insulin dependent diabetes was induced by administering a single intraperitoneal injection of alloxan monohydrate at a dose of $150 \mathrm{mg} / \mathrm{kg}$ to CD-1 mice. Aloesin (UP394) was formulated with an Aloe vera inner leaf gel powder polysaccharide (Qmatrix) to yield a composition designated UP780. Efficacy of oral administration of UP780 at $2000 \mathrm{mg} / \mathrm{kg}$ and its constituents (aloesin at $80 \mathrm{mg} / \mathrm{kg}$ and Qmatrix at $1920 \mathrm{mg} / \mathrm{kg}$ ) were evaluated in this model. Glyburide, a sulfonylurea drug used in the treatment of type 2 diabetes, was used at $5 \mathrm{mg} / \mathrm{kg}$ as a positive control. Effect of UP780 on non-diabetic normal mice was also addressed.

Results: Mice administered intraperitoneal alloxan monohydrate developed progressive type-1 diabetes like symptom. After 4 weeks of daily oral administration, reductions of 35.9\%, 17.2\% and $11.6 \%$ in fasting blood glucose levels were observed for UP780, the UP780 Aloe vera inner leaf gel polysaccharide preparation without chromone (Qmatrix), and Aloesin (UP394), treated animals respectively, compared to vehicle treated animals. UP780 has no impact on blood glucose level of non-diabetic healthy mice. UP780 showed statistically significant improvement for blood glucose clearance in oral glucose tolerance tests. Similarly, enhanced improvement in plasma insulin level and statistically significant reduction in triglyceride level was also observed for animals treated with the composition.

Conclusion: These findings suggest that UP780, a chromone standardized Aloe based composition, could possibly be used as a natural supplement alternative to facilitate maintenance of healthy blood glucose levels.

Keywords: Insulin resistance, Aloe vera, Chromones, Alloxan

\section{Introduction}

Ethnobotanical archives reveal that more than 800 plants have been used as an alternative remedies for the treatment of high blood glucose associated human ailments with minor or no scientific evidence. It's not uncommon to find Aloe as an alternative solution in this front line for many years. Aloe is a biochemically complex plant that contains many biologically active substances [1]. Historically, Aloe products have been used in dermatological

\footnotetext{
* Correspondence: myimam@unigen.net

Unigen, Inc, 3005 1st Ave, Seattle, WA 98121, USA
}

applications for the treatment of burns, sores and wounds. These uses have stimulated a great deal of research in identifying polysaccharides, chromones, anthraquinones and other compounds from Aloe plants that have clinical implications as anti-inflammatory [2,3] anti-tumor, antigastric ulcer, anti-diabetic, anti-tyrosinase [4] and antioxidant activity [5].

Aloe vera, also with a Latin name Aloe barbadensis, leaves and their bitter principles exhibit effects on blood glucose level in normal and alloxan-induced diabetic 
mice [6], and dried sap of various Aloe species demonstrates anti-diabetic activity in clinical studies [7].

Chromones are a specific type of aromatic compounds having a benzopyran-4-one as their major skeletal structure as illustrated by the Figure 1. Chomones isolated from various Aloe species have been reported to have diverse biological activity. Aloesin have reportedly inhibited tyrosinase activity [8] and up-regulate cyclin E-dependent kinase activity [9]. Those chromones isolated from Aloe barbadensis also demonstrate anti-inflammatory [10] and antioxidant activity [11].

A large diversity of animal models has been developed to better understand the pathogenesis of insulin dependent diabetes and new drugs have been introduced into the market to treat the primary cause or to prevent the catastrophe of its complications. Among these models, alloxan induced diabetes model is by far the most frequently used model which has been useful for the study of multiple aspect of the disease [12,13].

Alloxan, as a cytotoxic agent to the insulin-secreting $\beta$ cells of the pancreas, effectively induces insulin dependent phenotypes that resemble type 1 diabetes or post-beta cell "burnout" type 2 diabetes in a wide variety of animal models $[12,13]$. Thus, it allows elucidation of antihyperglycemic agents in the treatment of diabetes. Alloxan-induced diabetes consistently produced the main characteristics of diabetes mellitus including polydipsia, polyphagia, polyuria, decreased insulin levels, weight loss and hyperglycemia.

Though lifestyle intervention, mainly diet and exercise, remain as the ultimate behavioral change in managing metabolic syndrome and diabetic conditions; it is desirable to have safe nutritional approaches for preventing and/or ameliorating insulin resistance. In this frontier use of dietary supplements could be a potential option to control diabetic conditions. To date, many plant derived extracts have been studied, reported and commercialized for glucose lowering effects. However, very few of them are supported by credible chemical profiles, pre-clinical and clinical trial data to support associated claims.

The present study was therefore designed to evaluate a standardized composition, UP780, an aloe chromone formulated with an aloe polysaccharide, improves insulin sensitivity in alloxan induced insulin dependent diabetic mice.

\section{Materials and methods}

Animals and housing

Purpose bred female CD-1 mice, weighing 18-24 g, were purchased from USDA approved laboratory animal vendor (Charles River Laboratories, Inc., Wilmington,

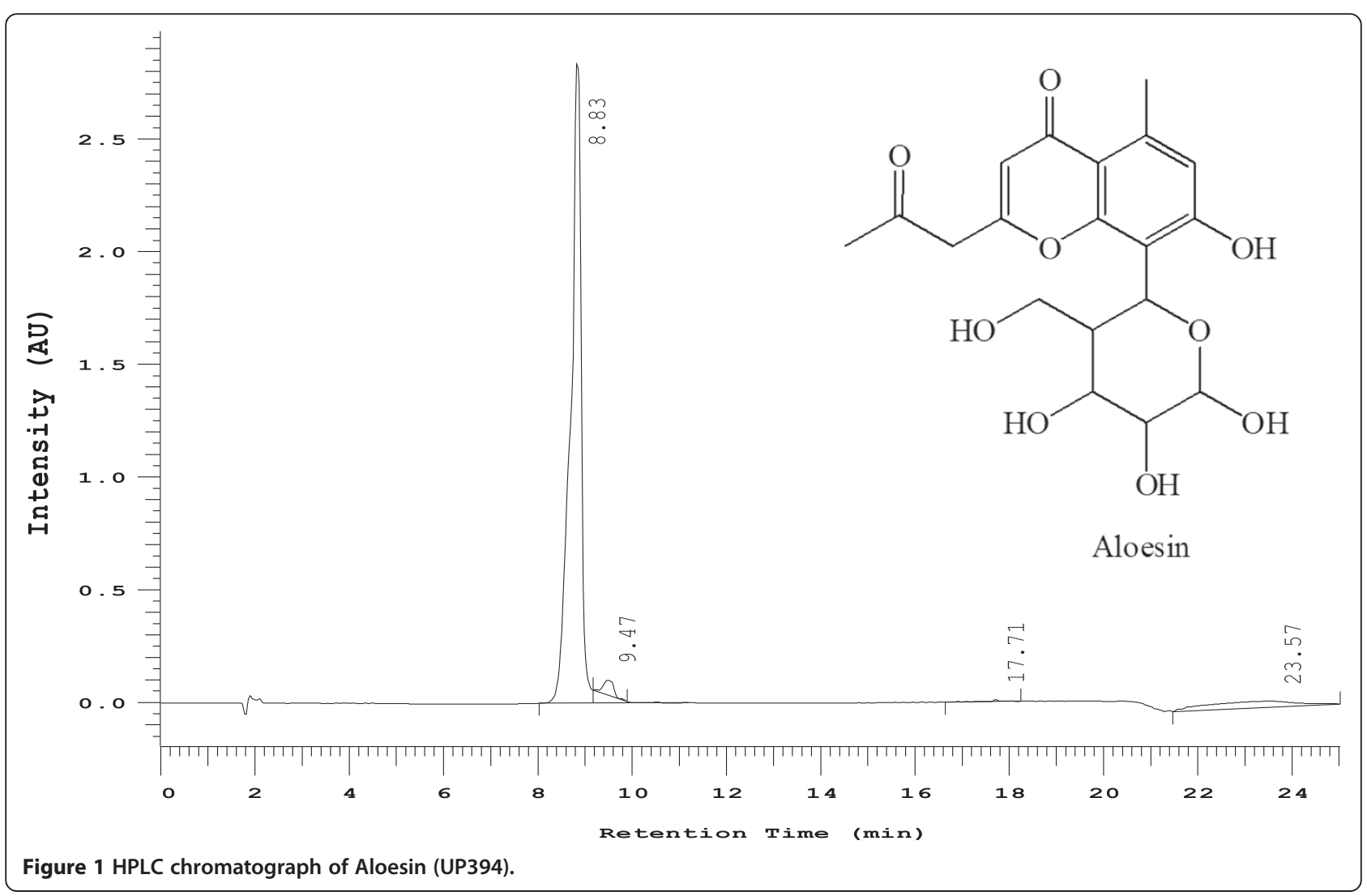


MA) and acclimated upon arrival for a week. Individual cages were identified with a cage card indicating project number, test article, dose level, group, and animal number. The Harlan T7087 soft cob beddings was used and changed at least twice/week. Animals were provided with fresh water and rodent chow diet \# T2018 (Harlan Teklad, 370 W, Kent, WA) ad libitum and were housed in a temperature controlled room $\left(22.2^{\circ} \mathrm{C}\right)$ on a 12 hour light-dark cycle. All animal experiments were conducted according to institutional guidelines congruent with the guide for the care and use of laboratory animals. All animal experiments were conducted according to institutional guidelines congruent with the guide for the care and use of laboratory animals. IACUC approval reference \#: UAS-101205.

\section{Model induction and dosing}

To induce disease model, overnight fasted mice received a single injection of alloxan monohydrate (Sigma Chemical, St. Louis, OH) at a dose of $150 \mathrm{mg} / \mathrm{kg}$ body weight intraperitoneally $[12,13]$. The induction of alloxan-induced diabetes was confirmed by measuring blood glucose level on the $5^{\text {th }}$ day after alloxan administration. Mice with glucose levels above $200 \mathrm{mg} / \mathrm{dl}$ were selected for randomized grouping. Average blood glucose levels for the groups ranged between $368-389 \mathrm{mg} / \mathrm{dl}$. Two group of mice ( $n=15$ /group) which did not receive alloxan served as the non-diabetic control (one group treated with vehicle and the other group treated with UP780 at $2000 \mathrm{mg} / \mathrm{kg}$ ).

Once an induction of the disease was confirmed and randomization was completed, daily oral treatment was initiated. Fresh test compounds and positive control were prepared each day and delivered orally to mice $(\mathrm{N}=15)$ at a dose of $2000 \mathrm{mg} / \mathrm{kg}$ standardized composition (UP780), $1920 \mathrm{mg} / \mathrm{kg}$ Aloe vera inner leaf gel powder polysaccharide (Qmatrix) and $80 \mathrm{mg} / \mathrm{kg}$ chromone aloesin (UP394) (Figure 1). Previously we have shown $200 \mathrm{mg} / \mathrm{kg}$ as the effective dose of UP780 in high fat diet induced diabetic mice. 10 times the effective dose $(2000 \mathrm{mg} / \mathrm{kg}$ ) were selected in the current study to evaluate the impact of UP780 in the blood glucose level of diseased and normal mice. The composition UP780, comprised of $4 \%$ aloesin and $96 \%$ aloe vera and hence a dose of $80 \mathrm{mg} / \mathrm{kg}$ and $1920 \mathrm{mg} / \mathrm{kg}$, respectively, were used for this study. The positive control group received $5 \mathrm{mg} / \mathrm{kg}$ Glyburide. Treatment lasted for 4 weeks. Research grade de-ionized water was used for suspending test compounds. The positive control, Glyburide, was first dissolved in DMSO and mixed with $0.25 \%$ of methylcellulose (Spectra, Lot\# 116H0857) and $0.5 \%$ of Tween 20 (Sigma, Lot \# 036 K00961) at 10\%. Test compounds were repeatedly vortexed between gavages to maintain consistent dosing. The carrier vehicle treated animals received deionized water only. No detectable sign of irritation was observed from drug or vehicle administration.

\section{Fasting glucose, triglyceride and plasma insulin}

Fasting blood glucose and triglyceride were taken at preinduction, week-0 (baseline), week-2 and week-4 after treatment of overnight fasted mice. Plasma insulin levels were determined at pre-induction, baseline (week-0) and week-4.

\section{Oral glucose tolerance test (OGTT)}

Oral glucose tolerance test (OGTT) was conducted 4week after onset of treatment $[14,15]$. On the test day, animals were fasted for 5 hours and received oral administration of glucose at a dose of $2 \mathrm{~g} / \mathrm{kg}$. Blood glucose levels were determined at time 0 (before glucose injection), and at 30, 60, 90, and 120 minutes post glucose delivery. Blood samples were obtained from the tail

\section{Assays}

Blood glucose levels were measured using the IQ blood glucose monitor with prestige test strips (Walgreen, Home Diagnostics, Inc., Ft. Lauderdale, FL). Total triglyceride levels were measured using the CardioChek Analyzer with PTS panels test strips (Polymer Technology System, Inc, Indianapolis, IN). Plasma insulin levels were measured with an ELISA kit and accompanied protocol for insulin (Crystal Chem - Chicago, IL). In brief, a mouse insulin ELISA kit was purchased from Crystal Chemical (Cat\# 90080) to test the insulin content of mouse plasma. The provided sample diluent $(95 \mu \mathrm{L})$ was dispensed into each well of a 96-well antibody-coated microplate. Samples and insulin standards $(5 \mu \mathrm{L})$ were added to the wells in duplicate and plates were incubated for 2 hours at $4^{\circ} \mathrm{C}$. Each well was then washed five times with the provided wash buffer. The anti-insulin enzyme conjugate $(100 \mu \mathrm{L})$ was added to each well and the microplate was incubated at room temperature for 30 minutes. Each well was washed seven times with the provided wash buffer and the enzyme substrate $(100 \mu \mathrm{L})$ was then added to each well. The microplate was incubated at room temperature for $40 \mathrm{mi}$ nutes before adding enzyme reaction stop solution $(100 \mu \mathrm{L})$ to each well. Each plate was read on a Wallac Victor $^{2}$ microplate reader at $A_{450}$ with $A_{570}$ values subtraction. Insulin concentration of the samples was calculated using the standard curve created by the insulin standards. Blood was collected by tail vein and spun down for plasma.

\section{Statistical analysis}

Data were analyzed using Sigmaplot (Version 11.0). The results are represented as mean \pm one S.D. Statistical significance between groups was calculated by means of single factor analysis of variance followed by a paired $t$-test. $P$-values less or equal to $0.05(\mathrm{P} \leq 0.05)$ were considered as significant. When normality test failed, for non-parametric analysis, data were subjected to Mann- 
Whitney sum ranks for $t$-test and Kruskal-Wallis one way analysis of variance on ranks for ANOVA. A conventional trapezoid rule was used to determine area under the curve ( $\left.\mathrm{AUCt}_{0-120}\right)$ for glucose tolerance test.

\section{Results}

Mice administered a single intraperitoneal injection of alloxan monohydrate at a dose of $150 \mathrm{mg} / \mathrm{kg}$ showed progression of type-I diabetes symptoms (Figure 2). As seen from the data in Figure 2, fasting blood glucose levels were reduced versus vehicle treatment following two weeks of oral treatment with Glyburide (39.1\% reduction), UP780 (39.1\% reduction), aloesin (14.5\% reduction), and Qmatrix (19.6\% reduction). Similarly, after 4-weeks of oral treatment with Glyburide, UP780, UP394 and Qmatrix, a $21.4 \%, 35.9 \%, 11.6 \%$ and $17.2 \%$ reduction in fasting blood glucose was measured for each respective treatment group compared to the vehicle control group. Only UP780 and glyburide showed statistically significant reduction in blood glucose level at both weeks $2(\mathrm{P}=0.00001$, $\mathrm{P}=0.003$, respectively) and week-4 $(\mathrm{P}=0.0001, \mathrm{P}=0.01$, respectively). Qmatrix treated animals showed statistically significant decrease in blood glucose level at week 2 $(\mathrm{P}=0.01)$. Fasting blood glucose levels for UP780 or vehicle treated non-diabetic normal mice, i.e., without alloxan administered, were unaffected at each time points monitored.

From oral glucose tolerance test (OGTT) data, it was observed that mice treated with $2000 \mathrm{mg} / \mathrm{kg}$ of UP780 or $5 \mathrm{mg} / \mathrm{kg}$ glyburide showed significantly improved clearance of blood glucose at each time point monitored versus vehicle treated diabetic mice (Table 1). Other treatment groups showed similar blood glucose clearance to that of vehicle after oral glucose load. Normal mice treated with vehicle or UP780 showed equivalent glucose utilization that was superior to all other treatment groups. As illustrated in area-under-the curve $\left(\mathrm{AUC}_{\mathrm{t} 0-\mathrm{t} 120}\right)$ of blood glucose levels from the OGTT data, UP780 has statistically significant low levels of blood glucose than either aloesin or Qmatrix (Figure 3). Similarly statistical significant reductions in total triglyceride level were observed both at week- 2 and week-4 for mice treated with UP780. However, these triglyceride reductions were statistically significant only at week-2 for aloesin and week-4 for Qmatrix. In contrast, the values were unaffected for non-diabetic mice treated either vehicle or UP780 (Table 2).

Plasma insulin levels were also measured to assess disease progression and severity. As presented in Table 3, post alloxan-induction plasma insulin levels were found to be the same or lower than pre-induction plasma insulin levels across all treatment groups. After four weeks of treatment, a similar trend of increased plasma insulin level was observed for all treatment groups including vehicle except for aloesin treated animals. The aloesin treatment group at week- 4 showed a $4.8 \%$ reduction in insulin levels from pre-treatment baseline values. However, this increase of plasma insulin level for alloxan-induced diabetic animals treated with glyburide and UP780 at week-4 was doubled to that observed in the vehicle plus alloxan control group.

\section{Discussion}

Significant reports have demonstrated the glucose lowering effect of Aloe plant in animal models. For instance, reductions in fasting blood glucose and triglyceride levels [16], improved liver gluconeogenesis and improved lipid profiles $[17,18]$, decreased oxidative brain damage $[19,20]$ decreased lipid peroxidation in kidney [21] and liver [22] in streptozotocin induced diabetic rats; improved insulin resistance and impaired glucose tolerance in high-fat diet-induced $[23,24]$ and $\mathrm{db} / \mathrm{db}$

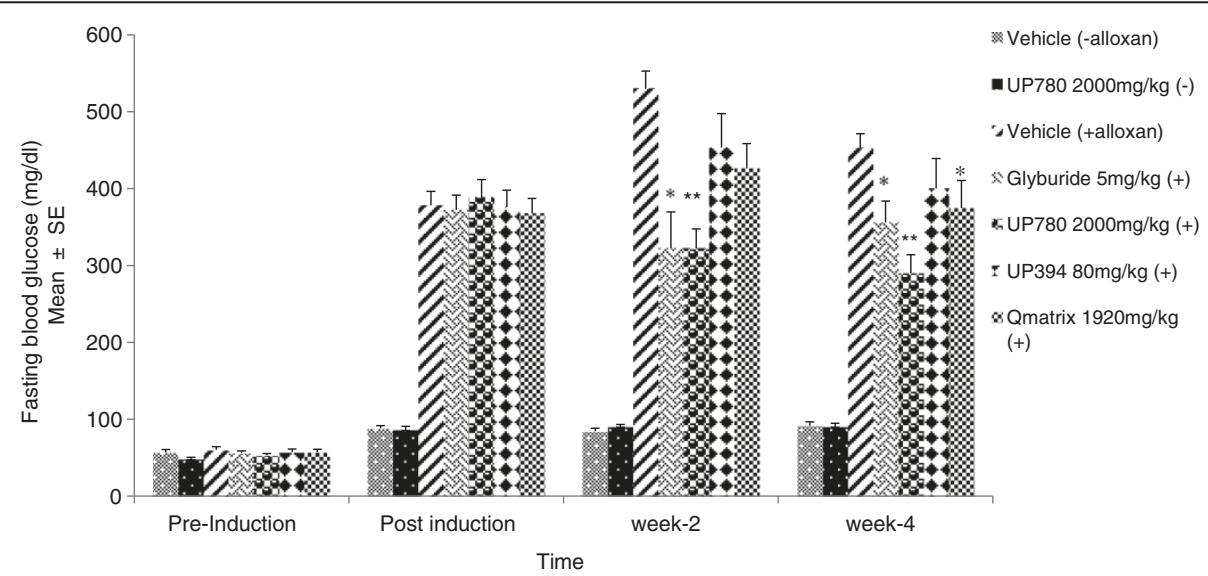

Figure 2 Fasting blood glucose level. Insulin dependent diabetes was induced by administering a single intraperitoneal injection of alloxan monohydrate at a dose of $150 \mathrm{mg} / \mathrm{kg}$ to CD-1 mice. Mice ( $n=15 / \mathrm{group}$ ) were fasted overnight before measurements were taken for fasting blood glucose levels at pre-induction, week-0 (baseline), week-2 and week-4 after treatment. Data are expressed as mean \pm SD. ${ }^{*} P \leq 0.05$. 
Table 1 Oral glucose tolerance test blood glucose values

\begin{tabular}{lcccccc}
\hline \multicolumn{7}{c}{ Blood glucose $(\mathbf{m g} / \mathbf{d l})$} \\
\hline Group & Dose $(\mathbf{m g} / \mathbf{k g})$ & T0 & T30 & T60 & T90 & T120 \\
\hline Vehicle (-alloxan) & 0 & $91.9 \pm 4.9$ & $125.2 \pm 5.3$ & $114.3 \pm 6.4$ & $93.4 \pm 7.9$ & $98.3 \pm 5.4$ \\
UP780 (-) & 2000 & $90.5 \pm 4.2$ & $113.7 \pm 5.9$ & $108.5 \pm 4.0$ & $95.1 \pm 4.1$ & $85.3 \pm 3.3$ \\
Vehicle (+alloxan) & 0 & $452.6 \pm 18.9$ & $518.0 \pm 18.1$ & $492.0 \pm 22.6$ & $486.1 \pm 23.6$ & $431.9 \pm 21.2$ \\
Glyburide (+) & 5 & $355.8 \pm 21.6^{*}$ & $472.7 \pm 28.2$ & $438.5 \pm 28.4$ & $441.7 \pm 35.1$ & $398.7 \pm 19.1$ \\
UP780 (+) & 2000 & $289.9 \pm 24.2^{*}$ & $382.9 \pm 21.0^{*}$ & $331.2 \pm 33.0^{*}$ & $339.7 \pm 34.5^{*}$ & $315.1 \pm 34.9^{*}$ \\
UP394 (+) & 80 & $400.2 \pm 39.0$ & $432.9 \pm 33.0$ & $483.4 \pm 44.3$ & $462.9 \pm 47.5$ & $442.1 \pm 48.0$ \\
Qmatrix (+) & 1920 & $374.7 \pm 36.0$ & $494.4 \pm 32.0$ & $447.5 \pm 36.6$ & $458.2 \pm 43.0$ & $443.2 \pm 42.0$ \\
\hline
\end{tabular}

Insulin dependent diabetes was induced by administering a single intraperitoneal injection of alloxan monohydrate at a dose of 150 mg/kg to CD-1 mice. Oral glucose tolerance test (OGTT) was conducted 4-week after onset of treatment. On the test day, animals ( $\mathrm{N}=15 / \mathrm{group})$ were fasted for 5 hours and received oral administration of glucose at a dose of $2 \mathrm{~g} / \mathrm{kg}$. Blood glucose levels were determined at time 0 (before glucose injection), and at $30,60,90$, and 120 minutes post glucose delivery. Blood samples were obtained from the tail. Data are expressed as mean $\pm \mathrm{SD}$. ${ }^{*} P \leq 0.05$.

non-insulin dependent diabetic mice [24,25] were reported.

In humans, hypoglycemic and hypolipidemic in Aloe vera gel preparation combined with psyllium seed husks [26], reduced blood glucose and triglyceride level in women treated with aloe vera gel alone [27] or men in combination with glibenclamide [28], lower fasting blood glucose levels when Aloe vera latex is given to noninsulin dependent diabetic patients [7], decreased levels of total serum cholesterol, triglycerides, and low-density lipoproteins when whole-leaf Aloe vera extract administered patients with hyperlipidemia [29], significant reductions in HbA1c, fructosamine, fasting glucose, and insulin when Aloe vera inner leaf gel powder standardized with $2 \%$ aloesin given to patients with prediabetes or metabolic syndrome [30] and anti-hyperglycemic and anti-hypercholesterolemic for hyperlipidemic type 2 diabetic patients in Aloe vera leaf gel [31] were reported.
It is very unusual though for either animal or human studies of natural ingredients in diabetes to adequately describe the composition used, including botanical species, plant part, active components and preparation, and to include an assessment of the dose. Similarly, activity of aloe as a glucose lowering agent could be affected by 1) processing 2) parts of the Aloe used 3) animal models selected and 4) structure and content of active components. Likewise some bioactive components such as chromones of Aloe are limited to the rinds of the plant and the manufacture processes usually removes them with other anthraquinone compounds [4]. Hence the current study was conducted to evaluate glucose lowering activity of a defined composition (UP780) of Aloe vera inner leaf gel powder (Qmatrix) with aloe chromones (aloesin) in insulin dependent alloxan induced type-1 diabetes model and non-diabetic healthy CD-1 mice.

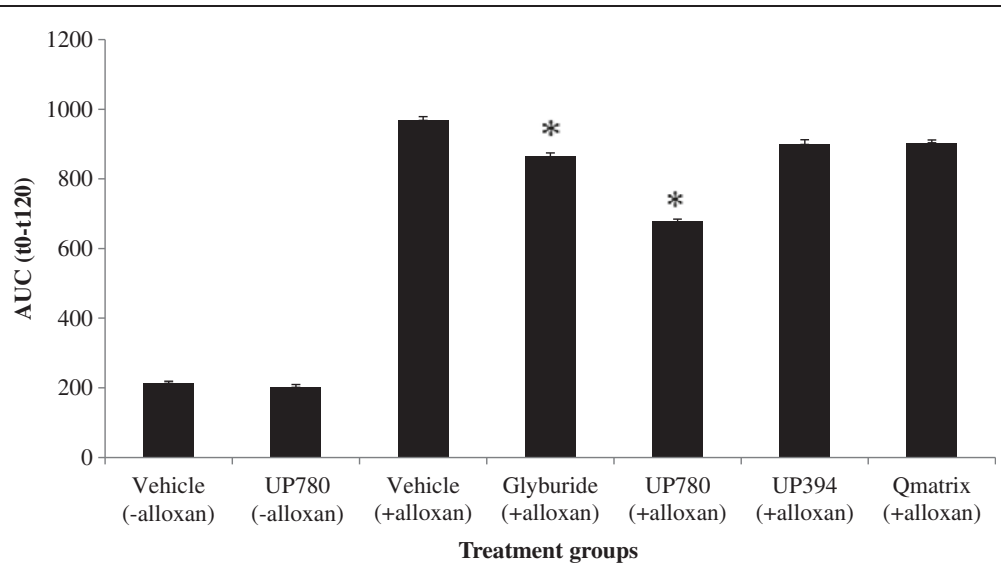

Figure 3 Area-under-concentration curve value of glucose in oral glucose tolerance test (AUC (t0-t120). Oral glucose tolerance test (OGTT) was conducted 4-week after onset of treatment. On the test day, animals ( $N=15 / \mathrm{group}$ ) were fasted for 5 hours and received oral administration of glucose at a dose of $2 \mathrm{~g} / \mathrm{kg}$. Blood glucose levels were determined at time 0 (before glucose injection), and at 30, 60, 90, and 120 minutes post glucose delivery. Blood samples were obtained from the tail. Data are expressed as mean \pm SD. A conventional trapezoid rule was used to determine area under the curve (AUCt $t_{0-120}$ ) for glucose tolerance test. ${ }^{*} P \leq 0.05$. 
Table 2 Fasting blood Triglyceride level

\begin{tabular}{lccccc}
\hline Group & $\begin{array}{c}\text { Dose } \\
(\mathbf{m g} / \mathbf{k g})\end{array}$ & $\begin{array}{c}\text { Priglyceride }(\mathbf{m g} / \mathbf{d} \mathbf{)}) \\
\text { Pre-induction } \\
\text { (Mean + SE) }\end{array}$ & $\begin{array}{c}\text { Post-induction } \\
\text { (Mean + SE) }\end{array}$ & $\begin{array}{c}\text { Week-2 } \\
\text { (Mean + SE) }\end{array}$ & $\begin{array}{c}\text { Week-4 } \\
\text { (Mean + SE) }\end{array}$ \\
\hline Vehicle (-alloxan) & 0 & $125.1 \pm 10.7$ & $90.1 \pm 3.7$ & $119.7 \pm 4.6$ & $126.9 \pm 10.6$ \\
UP780 (-) & 2000 & $118.1 \pm 8.5$ & $92.3 \pm 3.6$ & $128.7 \pm 6.4$ & $110.5 \pm 5.5$ \\
Vehicle (+alloxan) & 0 & $141.1 \pm 7.3$ & $111.5 \pm 37.6$ & $167.8 \pm 20.0$ & $144.0 \pm 14.2$ \\
Glyburide (+) & 5 & $135.3 \pm 32.0$ & $134.6 \pm 37.5$ & $124.0 \pm 8.8^{*}$ & $124.3 \pm 8.2^{*}$ \\
UP780 (+) & 2000 & $133.5 \pm 7.8$ & $117.5 \pm 10.0$ & $116.6 \pm 8.41^{*}$ & $128.2 \pm \pm 11.7$ \\
UP394 (+) & 80 & $135.2 \pm 8.2$ & $121.3 \pm 16.1$ & $119.7 \pm 17.1$ & $113.8 \pm 30.3^{*}$ \\
Qmatrix (+) & 1920 & $130.5 \pm 10.1$ & $101.4 \pm 7.3$ & & 138.8 \\
\hline
\end{tabular}

Insulin dependent diabetes was induced by administering a single intraperitoneal injection of alloxan monohydrate at a dose of $150 \mathrm{mg} / \mathrm{kg}$ to $\mathrm{CD}-1 \mathrm{mice}$. Measurements for fasting blood triglyceride were taken at pre-induction, week-0 (baseline), week-2 and week-4 after treatment. Data are expressed as mean \pm SD. ${ }^{*} P \leq 0.05$.

Mice received a single injection of intraperitoneal alloxan monohydrate at a dose of $150 \mathrm{mg} / \mathrm{kg}$ per day showed type 1 diabetes phenotype. Both UP780 and glyburide improved fasting blood glucose levels and glucose tolerance, and increased insulin levels to a greater extent than the UP780 constituents, aloesin and Qmatrix.

Plasma insulin level was also measured to estimate degree of disease progression and severity in alloxan induced diabetes model. Post induction plasma insulin level was found lower than pre-induction across treatment groups including vehicle treated mice except for non-diabetic mice treated with vehicle or UP780. After 28 days of daily oral treatment, a similar trend in increase plasma insulin level was observed for all treatment groups including vehicle except UP394 treated animals that showed $4.8 \%$ reduction from baseline. An increase in plasma insulin levels was also seen for vehicle treated, though less than $50 \%$ that seen with UP780 and glyburide. This result with vehicle treated mice suggests regeneration of beta-cells or compensatory conversion of alpha-cells to produce insulin accounts for some of the increase in insulin [32].
The increase in plasma insulin level observed for UP780 treated non-diabetic mice was consistent to that of vehicle treated non-diabetic mice. In week 4 , the plasma insulin level of mice with no alloxan injection was 7.5 - 9.6 fold higher than that of the vehicle control mice with alloxan. This surge of plasma insulin level could be the result of metabolic compensation occurred after fasting in response to hypoglycemia. However, neither UP780 nor vehicle affects blood glucose level of healthy mice. Substantiating our finding Okyar et al. [33], have reported the neutral effect of Aloe vera leaf pulp and gel extracts on blood glucose level of nondiabetic rats.

Possibly UP780 could partially incurred its activity in this model through protection and/or stimulation of existing beta-cells to produce increased level of insulin. Clearly interestingly though, an unexpected synergy was observed from the combination of aloesin with aloe polysaccharidein that the beneficial effects seen with UP780 treatment exceed that predicted based on simply summing the effects observed for each of its constituents. The reduction in fasting blood glucose level of diabetic mice in

Table 3 Plasma insulin level

\begin{tabular}{|c|c|c|c|c|c|}
\hline \multicolumn{6}{|c|}{ Plasma insulin (ng/ml) } \\
\hline Group & $\begin{array}{l}\text { Dose } \\
(\mathrm{mg} / \mathrm{kg})\end{array}$ & $\begin{array}{l}\text { Pre-induction } \\
\text { (Mean + SE) }\end{array}$ & $\begin{array}{l}\text { Post-induction } \\
\text { (Mean + SE) }\end{array}$ & $\begin{array}{c}\text { Week-4 } \\
\text { (Mean + SE) }\end{array}$ & $\begin{array}{c}\% \text { change } \\
\text { after treatment }\end{array}$ \\
\hline Vehicle (-alloxan) & 0 & $1.25 \pm 0.27$ & $1.23 \pm 0.29$ & $4.26 \pm 0.36$ & $246.3 \uparrow$ \\
\hline UP780 (-) & 2000 & $0.99 \pm 0.14$ & $0.99 \pm 0.27$ & $4.12 \pm 0.39$ & $316.2 \uparrow$ \\
\hline Vehicle (+alloxan) & 0 & $1.78 \pm 0.27$ & $1.50 \pm 0.34$ & $1.99 \pm 0.24$ & $32.7 \uparrow$ \\
\hline Glyburide (+) & 5 & $1.87 \pm 0.33$ & $1.10 \pm 0.15$ & $1.76 \pm 0.50$ & $60.0 \uparrow$ \\
\hline UP780 (+) & 2000 & $1.96 \pm 0.31$ & $1.48 \pm 0.33$ & $2.37 \pm 0.41$ & $60.1 \uparrow$ \\
\hline UP394 (+) & 80 & $2.48 \pm 0.5$ & $1.68 \pm 0.48$ & $1.60 \pm 0.37$ & $4.8 \downarrow$ \\
\hline Qmatrix (+) & 1920 & $1.89 \pm 0.28$ & $1.50 \pm 0.21$ & $1.69 \pm 0.32$ & $12.7 \uparrow$ \\
\hline
\end{tabular}

Insulin dependent diabetes was induced by administering a single intraperitoneal injection of alloxan monohydrate at a dose of 150 mg/kg to CD-1 mice. Measurements for plasma insulin were taken at pre-induction, week-0 (baseline), and week-4 after treatment. Data are expressed as mean \pm SD as well as percent change of treatment. $\uparrow$ increase from post induction, $\downarrow$ decrease from post induction. 
the present investigation clearly reveals UP780 possess potential antidiabetic activity. UP780, comprised of $4 \%$ aloesin and $96 \%$ aloe vera, could have assisted surviving $\beta$-cells to resist the oxidative damage or prevent further damage caused by alloxan. Alloxan, as a cytotoxic agent to the insulin-secreting $\beta$ cells of the pancreas, effectively induces insulin dependent phenotypes that resemble type 1 diabetes or post-beta cell "burnout" type 2 diabetes. In a way, the daily administration of UP780 would lead to the presence of known anti-oxidants such as aloesin and aloe polysaccharides as a shield providing an antioxidant activity to the $\beta$-cells of the islets of Langerhans from the destruction caused by superoxide radicals derived from alloxan $[10,11,16]$. In addition, the possibility of glyburide enhancing $\beta$-cells responsiveness to glucose has also been reported [34]. This mechanism of action could also be another possibility of UP780 to alleviate hyperglycemia; however, further detailed investigation mainly focused on the mode of action of UP780 could shed a better understanding how the composition be better utilized in targeting the pathogenesis of diabetes. In fact some have suggested that hypoglycemic activity of aloe observed in alloxan induced insulin dependent mouse model could be associated with its radical scavenging activity [23,35-37] or stimulate synthesis and/or release of insulin from beta-cell of pancreases [6].

Parallel to our result, Ghannnam et al. [7] showed that glibenclamide and aloe have statistically significant impact in reducing fasting blood glucose level in diabetic mice induced by alloxan. In this study, diabetic mice were given $10 \mathrm{mg} / \mathrm{kg}$ and $500 \mathrm{mg} / \mathrm{kg}$ of glibenclamide and aloe, respectively, twice per day for 14 days. Fasting blood glucose level was found significantly lower for both treatment groups after 3 days of treatment; however, after a week only the aloe treated mice showed the significance. In another study conducted by Ajabnoor (1990) also showed that when aloe was given for 4 days at $500 \mathrm{mg} / \mathrm{kg}$ twice per day, significant reduction in fasting blood glucose level were observed in alloxan induced diabetic mouse.

\section{Conclusion}

Clinically it has been reported that UP780 can result in a statistically significant reduction in $\mathrm{HbA} 1 \mathrm{C}$, fasting blood glucose, fructosamine and plasma insulin level [34]. In addition to the data depicted here, previously we have shown that UP780 could improve impaired glucose and insulin resistance in high-fat diet-induced and $\mathrm{db} / \mathrm{db}$ non-insulin dependent diabetic mouse models. Therefore, UP780, a standardized Aloe chromone based composition, could possibly be considered as a natural supplement alternative to maintain healthy blood glucose level.

\section{Competing interests}

All authors, except Mandee Pantier and Jifu Zhao, are currently Unigen employees, therefore with financial interests.

\section{Authors' contributions}

MY conceived and designed, carried out study, data calculation, statistical analysis, data interpretation, and drafted/edited the manuscript. MP assisted in conducting the study. BC carried out the ELISA assay for plasma insulin. JZ conducted structure elucidations and identification. QJ and LB conceived the study, participated in its design, interpreted data, and edited the manuscript. All authors read and approved the final manuscript.

\section{Acknowledgment}

The authors would like to express their best gratitude to Mr. Ken Jones from Aloecorp; Dr. Padmapriya Abeysinghe, and Dr. Wenwen Ma from Unigen for their invaluable support for the completion of this project.

Received: 10 January 2014 Accepted: 18 May 2014

Published: 24 May 2014

\section{References}

1. Cohen IK, Diegelmann RF, Lindblad WJ: Wound Healing: Biochemical \& Clinical Aspects. Philadelphia: Saunders; 1992

2. Grindlay D, Reynolds T: The Aloe vera phenomenon: a review of the properties and modern uses of the leaf parenchyma gel. J Ethnopharmacol 1986, 16:117-151.

3. Hart LA, van Enckevort PH, van Dijk H, Zaat R, de Silva KT, Labadie RP: Two functionally and chemically distinct immunomodulatory compounds in the gel of Aloe vera. J Ethnopharmacol 1988, 23:61-71.

4. Yagi A, Kanbara T, Morinobu N: Inhibition of mushroom-tyrosinase by aloe extract. Planta Med 1987, 53:515-517.

5. Yu BP, Lee KY: Identification of potent antioxidant from Aloe barbadensis U.S. Patent No. 5, 939, 395

6. Ajabnoor MA: Effect of aloes on blood glucose levels in normal and alloxan diabetic mice. J Ethnopharmacol 1990, 28:215-220.

7. Ghannam N, Kingston M, Al-Meshaal IA, Tariq M, Parman NS, Woodhouse N: The antidiabetic activity of aloes: preliminary clinical and experimental observations. Horm Res 1986, 24:288-294.

8. Jones K, Hughes J, Hong M, Jia Q, Orndorff S: Modulation of melanogenesis by aloesin: a competitive inhibitor of tyrosinase. Pigment Cell Res 2002, 15:335-340.

9. Lee KY, Park JH, Chung MH, Park YI, Kim KW, Lee YJ, Lee SK: Aloesin up-regulates cyclin E/CDK2 kinase activity via inducing the protein levels of cyclin E, CDK2, and CDC25A in SK-HEP-1 cells. Biochem Mol Biol Int 1997, 41:285-292.

10. Hutter JA, Salman M, Stavinoha WB, Satsangi N, Williams RF, Streeper RT, Weintraub ST: Antiinflammatory C-glucosyl chromone from Aloe barbadensis. J Nat Prod 1996, 59:541-543.

11. Lee KY, Weintraub ST, Yu BP: Isolation and identification of a phenolic antioxidant from Aloe barbadensis. Free Radic Biol Med 2000, 28:261-265.

12. Adeyi AO, Idowu BA, Mafiana CF, Oluwalana SA, Ajayi OL, Akinloye OA: Rat model of food-induced non-obese-type 2 diabetes mellitus: comparative pathophysiology and histopathology. Int J Physiol Pathophysiol Pharmacol 2012, 4:51-58

13. Xu Z, Wang $X$, Zhou M, Ma L, Deng $Y$, Zhang H, Zhao A, Zhang Y, Jia W: The antidiabetic activity of total lignan from Fructus Arctii against alloxan-induced diabetes in mice and rats. Phytother Res 2008, 22:97-101.

14. Attele AS, Zhou YP, Xie JT, Wu JA, Zhang L, Dey L, Pugh W, Rue PA, Polonsky KS, Yuan CS: Antidiabetic effects of Panax ginseng berry extract and the identification of an effective component. Diabetes 2002, 51:1851-1858.

15. Harach T, Aprikian O, Monnard I, Moulin J, Membrez M, Beolor JC, Raab T, Mace K, Darimont C: Rosemary (Rosmarinus officinalis L.) leaf extract limits weight gain and liver steatosis in mice fed a high-fat diet. Planta Med 2010, 76:566-571.

16. Rajasekaran S, Sivagnanam K, Subramanian S: Antioxidant effect of Aloe vera gel extract in streptozotocin-induced diabetes in rats. Pharmacol Rep 2005, 57:90-96.

17. Rajasekaran S, Ravi K, Sivagnanam K, Subramanian S: Beneficial effects of aloe vera leaf gel extract on lipid profile status in rats with streptozotocin diabetes. Clin Exp Pharmacol Physiol 2006, 33:232-237. 
18. al-Awadi $F$, Fatania $H$, Shamte $U$ : The effect of a plants mixture extract on liver gluconeogenesis in streptozotocin induced diabetic rats. Diabetes Res 1991, 18:163-168.

19. Rajasekaran S, Sivagnanam K, Subramanian S: Modulatory effects of Aloe vera leaf gel extract on oxidative stress in rats treated with streptozotocin. J Pharm Pharmacol 2005, 57:241-246.

20. Parihar MS, Chaudhary M, Shetty R, Hemnani T: Susceptibility of hippocampus and cerebral cortex to oxidative damage in streptozotocin treated mice: prevention by extracts of Withania somnifera and Aloe vera. J Clin Neurosci 2004, 11:397-402.

21. Bolkent S, Akev N, Ozsoy N, Sengezer-Inceli M, Can A, Alper O, Yanardag R Effect of Aloe vera (L.) Burm. fil. leaf gel and pulp extracts on kidney in type-II diabetic rat models. Indian J Exp Biol 2004, 42:48-52.

22. Can A, Akev N, Ozsoy N, Bolkent S, Arda BP, Yanardag R, Okyar A: Effect of Aloe vera leaf gel and pulp extracts on the liver in type-Il diabetic rat models. Biol Pharm Bull 2004, 27:694-698.

23. Kim K, Kim H, Kwon J, Lee S, Kong H, Im SA, Lee YH, Lee YR, Oh ST, Jo TH, Park YI, Lee CK, Kim K: Hypoglycemic and hypolipidemic effects of processed Aloe vera gel in a mouse model of non-insulin-dependent diabetes mellitus. Phytomedicine 2009, 16:856-863.

24. Yimam M, Zhao J, Corneliusen B, Pantier M, Brownell LA, Jia Q: UP780, a chromone-enriched aloe composition improves insulin sensitivity. Metab Syndr Relat Disord 2013, 11:267-275.

25. Tanaka M, Misawa E, Ito Y, Habara N, Nomaguchi K, Yamada M, Toida T, Hayasawa $H$, Takase M, Inagaki M, Higuchi R: Identification of five phytosterols from Aloe vera gel as anti-diabetic compounds. Biol Pharm Bull 2006, 29:1418-1422.

26. Agarwal OP: Prevention of atheromatous heart disease. Angiology 1985, 36:485-492.

27. Yongchaiyudha S, Rungpitarangsi $\mathrm{V}$, Bunyapraphatsara $\mathrm{N}$ Chokechaijaroenporn O: Antidiabetic activity of Aloe vera L. juice. I. Clinical trial in new cases of diabetes mellitus. Phytomedicine 1996, 3:241-243.

28. Bunyapraphatsara N, Yongchaiyudha S, Rungpitarangsi V, Chokechaijaroenporn O: Antidiabetic activity of Aloe vera L. juice II. Clinical trial in diabetes mellitus patients in combination with glibenclamide. Phytomedicine 1996, 3:245-248.

29. Nasiff HA, Fajardo FR, Velez F: Effect of aloe on hyperlipidemia in patients with negative response to diet. Revista Cubana Med Gen Integral 1993, 9:43-51.

30. Devaraj S, Yimam M, Brownell LA, Jialal I, Singh S, Jia Q: Effects of Aloe vera supplementation in subjects with prediabetes/metabolic syndrome. Metab Syndr Relat Disord 2013, 11:35-40.

31. Huseini HF, Kianbakht S, Hajiaghaee R, Dabaghian FH: Anti-hyperglycemic and anti-hypercholesterolemic effects of Aloe vera leaf gel in hyperlipidemic type 2 diabetic patients: a randomized double-blind placebo-controlled clinical trial. Planta Med 2012, 78:311-316.

32. Chung $\mathrm{CH}$, Hao E, Piran R, Keinan E, Levine F: Pancreatic beta-cell neogenesis by direct conversion from mature alpha-cells. Stem Cells 2010, 28:1630-1638.

33. Okyar A, Can A, Akev N, Baktir G, Sutlupinar N: Effect of Aloe vera leaves on blood glucose level in type I and type II diabetic rat models. Phytother Res 2001, 15:157-161.

34. Patanè G, Piro $S$, Anello M, Rabuazzo AM, Vigneri R, Purrello F: Exposure to glibenclamide increases rat beta cells sensitivity to glucose. Br J Pharmacol 2000, 129:887-892.

35. Beppu H, Koike T, Shimpo K, Chihara T, Hoshino M, Ida C, Kuzuya H: Radical-scavenging effects of Aloe arborescens Miller on prevention of pancreatic islet B-cell destruction in rats. J Ethnopharmacol 2003, 89:37-45.

36. Jain N, Vijayaraghavan R, Pant SC, Lomash V, Ali M: Aloe vera gel alleviates cardiotoxicity in streptozocin-induced diabetes in rats. J Pharm Pharmacol 2010, 62:115-123.

37. Lenzen S: The mechanisms of alloxan- and streptozotocin-induced diabetes. Diabetologia 2008, 51:216-226.

doi:10.1186/1758-5996-6-61

Cite this article as: Yimam et al.: Blood glucose lowering activity of aloe based composition, UP780, in alloxan induced insulin dependent mouse diabetes model. Diabetology \& Metabolic Syndrome 2014 6:61.

\section{Submit your next manuscript to BioMed Central and take full advantage of:}

- Convenient online submission

- Thorough peer review

- No space constraints or color figure charges

- Immediate publication on acceptance

- Inclusion in PubMed, CAS, Scopus and Google Scholar

- Research which is freely available for redistribution 